\title{
Flora da Bahia: Putranjivaceae
}

\section{Lucas Cardoso Marinho ${ }^{* *}$ \& André Márcio Amorim²,a}

${ }^{1}$ Programa de Pós-Graduação em Botânica, Departamento de Ciências Biológicas, Universidade Estadual de Feira de Santana, Bahia, Brasil.

${ }^{2}$ Herbário CEPEC, Centro de Pesquisas do Cacau e Departamento de Ciências Biológicas, Universidade Estadual de Santa Cruz, Bahia, Brasil.

Resumo - O levantamento florístico de Putranjivaceae da Bahia é aqui apresentado como contribuição ao conhecimento da flora do Estado. É reconhecida apenas uma espécie, Drypetes sessiliflora, da Floresta Atlântica. São apresentados descrição, ilustração, mapa de distribuição geográfica na Bahia e comentários sobre os táxons.

Palavras-chave adicionais: Drypetes, florística, Malpighiales, Nordeste brasileiro, taxonomia.

Abstract (Flora of Bahia: Putranjivaceae) - A floristic inventory of Putranjivaceae in Bahia is presented as a contribution to the study of the flora of the state. Only one species, Drypetes sessiliflora, from the Atlantic rain forest, is recognized. Descriptions, illustrations, a map of geographic distribution in Bahia and general comments for the taxa are provided.

Additional key words: Drypetes, floristics, Malpighiales, Northeast Brazil, taxonomy.

\section{Putranjivaceae}

Árvores ou arbustos, dioicos ou monoicos; tricomas presentes ou ausentes. Folhas alternas, simples, dísticas, margens inteiras ou serrilhadas, pecioladas, peninérveas; estípulas pouco evidentes. Inflorescências fasciculadas, axilares ou caulifloras. Flores unissexuadas, actinomorfas, monoclamídeas, dialissépalas; sépalas 4 ou $5(-7)$; prefloração imbricada. Flores estaminadas sésseis ou pediceladas,

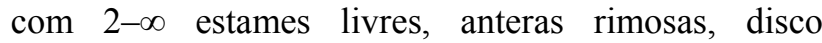
nectarífero intraestaminal presente. Flores pistiladas pediceladas ou sésseis, disco nectarífero presente ou ausente, ovário súpero, 1-3(-9)-carpelar, 1-3(-9)locular, placentação axial, lóculos biovulados. Frutos indeiscentes, drupáceos; sementes ecarunculadas.

Putranjivaceae pertence à ordem Malpighiales. Foi estabelecida a partir de estudos com base em dados moleculares, que subdividiram as Euphorbiaceae sensu lato em quatro grupos com base no número de óvulos por lóculo do ovário: Euphorbiaceae sensu stricto, Phyllanthaceae, Putranjivaceae e Picrodendraceae (APG II 2003; Wurdack et al. 2004, 2005; APG III 2009). Essas três últimas famílias apresentam lóculos biovulados (Secco et al. 2012), mas Putranjivaceae se diferencia das outras duas famílias por apresentar frutos drupáceos (vs. cápsulas) e sempre apresentar hábito arbóreo ou arbustivo (Wurdack et al. 2004). A família está posicionada em um clado ainda não totalmente resolvido, que engloba as Chrysobalanaceae, Dichapetalaceae e Malpighiaceae (Xi et al. 2012).

\footnotetext{
*Autor para correspondência: lcmarinho1@gmail.com;

aamorim.uesc@gmail.com

Editora responsável: Ana Maria Giulietti

Submetido: 13 set. 2013; aceito: 29 mar. 2014

Publicação eletrônica: 15 ago. 2014; versão final: 19 ago. 2014
}

Putranjivaceae está distribuída na região tropical e possui três gêneros: Drypetes (veja abaixo), além de Putranjiva Wall. e Sibangea Oliv., cada qual com três espécies distribuídas na África e Ásia (Steinmann 2001; Stevens 2014). No Brasil, está representada por Drypetes, que ocorre nos domínios da Floresta Attântica e Amazônia (Secco \& Cordeiro 2014).

\section{Drypetes Vahl}

Árvores ou arbustos, dioicos; tricomas presentes ou ausentes. Folhas coriáceas a papiráceas, margens inteiras ou serrilhadas; estípulas caducas ou pouco evidentes. Inflorescências axilares ou caulifloras. Flores com 4 ou 5 sépalas; Flores estaminadas pediceladas; disco nectarífero cupular ou lobado; estames 4-12. Flores pistiladas pediceladas ou sésseis, disco nectarífero anelado; ovário 1-3(-9)-locular; estigma subséssil. Frutos elipsoides, axilares.

Drypetes possui cerca de 200 espécies, principalmente concentradas na África e Ásia; 25 ocorrem nas Américas (Steinmann 2001). Das três espécies que ocorrem no Brasil, duas ocorrem na Região Norte, D. amazonica Steyerm. e D. variabilis Uittien, e uma, Drypetes sessiliflora, na Floresta Atlântica (Secco \& Cordeiro 2014).

Drypetes sessiliflora Allemão, Minerva Brasil. 2(24): 738. 1844.

Figuras 1-3.

Árvores 7-15 m alt.; tricomas ausentes. Folhas $10,3-19,6 \times 3,7-8,5 \mathrm{~cm}$, coriáceas a papiráceas, lanceoladas, ápice obtuso, base arredondada a atenuada, assimétrica, margens inteiras ou serrilhadas; pecíolo $0,5-1,8 \mathrm{~cm}$ compr.; estípulas caducas. Inflorescências com 3-10 flores por fascículo, axilares. Flores ca. $4 \mathrm{~mm}$ compr., verdes; sépalas 4, 2$3 \mathrm{~mm}$ compr., ápice obtuso, base truncada, externamente pubescentes, verdes. Flores estaminadas 


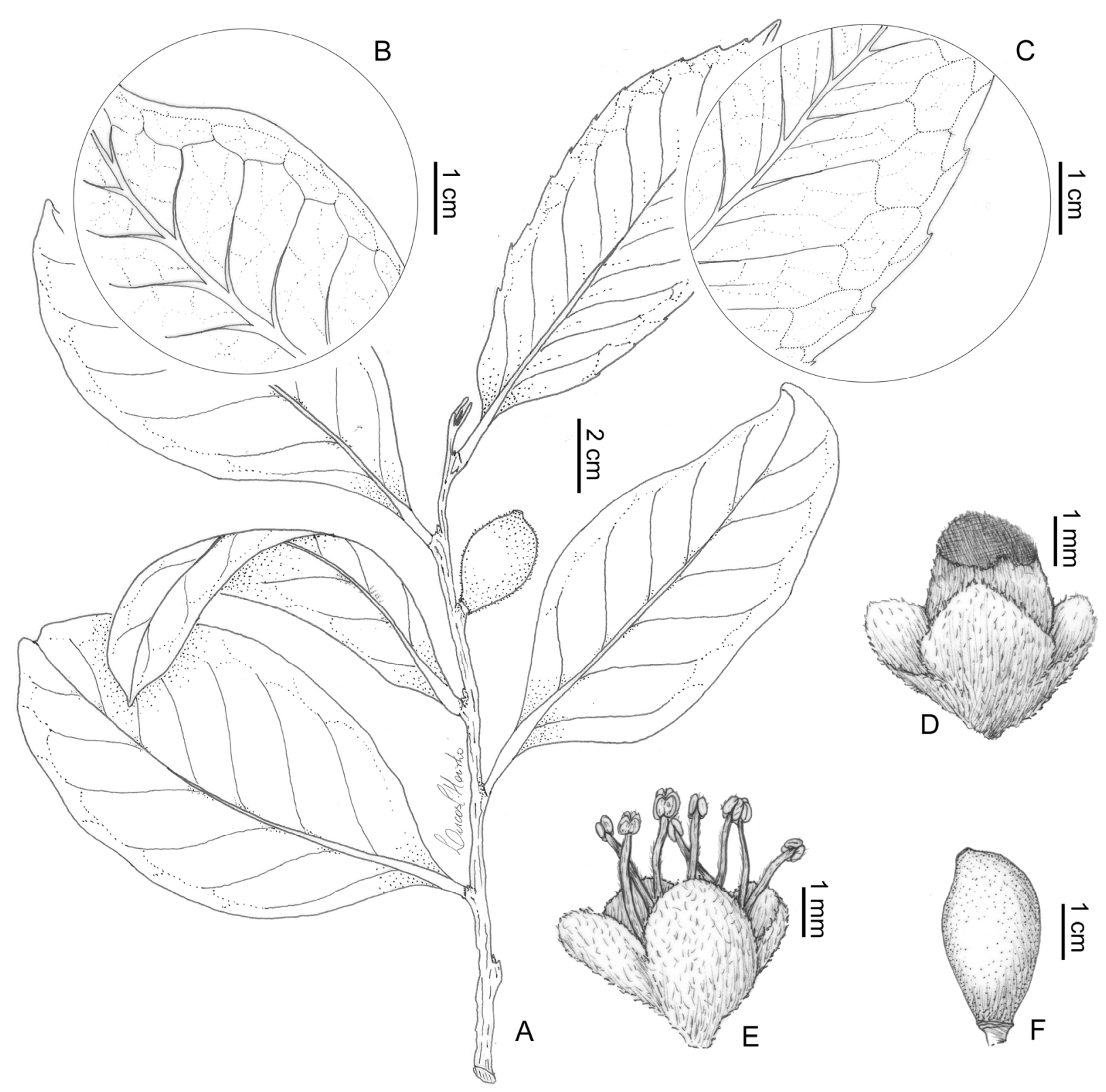

Figura 1. Drypetes sessiliflora: A- ramo com fruto; B- detalhe da lâmina foliar evidenciando a margem lisa; C- detalhe da lâmina foliar evidenciando a margem serrilhada; D- flor pistilada; E- flor estaminada; F- fruto (A-D e F- Santos 3862; E- Amorim 2581).

com 5 sépalas de tamanhos iguais, arredondadas; estames 8, livres, brancos a amarelados; filetes pubescentes; anteras eretas, basifixas. Flores pistiladas sésseis; sépalas 5, lanceoladas a deltoides; disco nectarífero anelado; ovário 3-locular. Drupas 2-3,2 $\times$ 1,2-1,7 cm, epicarpo velutino.

Espécie com distribuição na Floresta Atlântica, nos estados da Bahia e Rio de Janeiro (Secco \& Cordeiro 2014). G7, G8, H8, I8: florestas ombrófilas submontanas e de terras baixas, entre 50 a $400 \mathrm{~m}$ s.n.m., no sul do Estado. Coletada com flores estaminadas em novembro, flores pistiladas em fevereiro e frutos ao longo do ano.

Material examinado - Almadina, Serra dos Sete Paus, 14'44'6"S, 3940'46"W, 1 maio 2004 (fr.), J.L. Paixão et al. 355

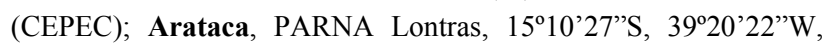

nov. 2006 (fr.), A.M. Amorim et al. 6582 (CEPEC); Canavieiras, fazenda Gromogô, $15^{\circ} 40^{\prime} \mathrm{S}, 38^{\circ} 56^{\prime} \mathrm{W}, 22$ jul. 1981 (est.), L.A. Mattos-Silva et al. 1336 (CEPEC); Ilhéus, RPPN Salto Apepique, 14³5'10”S, 3907'02”W, 19 fev. 2005 (fl. 우), P. Fiaschi et al. 2711 (CEPEC); Itacaré, PESC Conduru, 1402'15'S, 3903'55'W, 26 out. 2004 (bot.), P. Fiaschi et al. 2574 (CEPEC); Jussari, RPPN Serra do Teimoso, $15^{\circ} 10^{\prime} \mathrm{S}, 39^{\circ} 35^{\prime} \mathrm{W}, 8$ nov. 1998 (fl. §), A.M. Amorim et al. 2581 (CEPEC); Porto Seguro, Reserva BrasilHolanda de Indústrias, 16²7’45”S, 39¹9’31”W, 6 abr. 1994 (fr.), A.M. Carvalho et al. 4453 (CEPEC); Santa Cruz Cabrália, Estação Ecológica Pau-Brasil, 16²23'S, 39²' W, 17 jan. 1984 (est.), F.S. Santos 115 (CEPEC); Una, Maruim, fazenda Dois de Julho, 1517'S, 3904'W, 1 maio 1981 (est.), S.A. Mori et al. 13897 (CEPEC); Uruçuca, fazenda Lagoa do Conjunto Fazenda Santa Cruz, $14^{\circ} 25^{\prime}$ 'S, 39 $01^{\prime} \mathrm{W}, 12$ jul. 1991 (est.), W.W. Thomas et al. 7486 (CEPEC). 


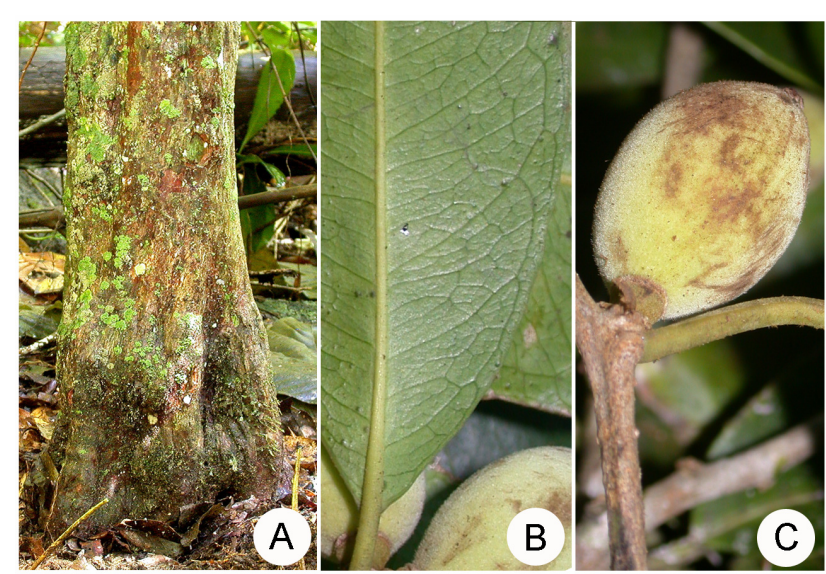

Figura 2. Drypetes sessiliflora: A- base do tronco; B- detalhe da face abaxial da lâmina foliar; C- fruto imaturo. (A, B- Amorim 6582, fotos: A-W.W. Thomas; B, C-A.M. Amorim).

Os materiais coletados na Bahia possuem dois padrões foliares distintos. As folhas com a margem inteira são geralmente maiores que as folhas com a margem serrilhada. Apesar da maioria dos espécimes apresentar apenas um desses padrões, existem indivíduos nos quais as duas formas de folhas estão presentes, não permitindo um reconhecimento formal dessa variação.

As flores esverdeadas e diminutas, dispostas em inflorescências axilares curtas de Drypetes sessiliflora passam frequentemente despercebidas. $\mathrm{Na}$ Bahia, grande parte das amostras dessa espécie foi obtida durante estudos de estrutura da comunidade arbórea. Este aspecto retrata a contribuição de estudos quantitativos para a documentação de grupos taxonômicos arbóreos que apresentam estruturas reprodutivas inconspícuas e de ocorrência predominantemente florestal.

\section{AgRADeCIMENTOS}

Ao $\mathrm{CNPq}$, pela bolsa de Mestrado concedida a LCM, pela bolsa de Produtividade em Pesquisa concedida a AMA (Processo 306992/2012-4) e pelo financiamento dessa pesquisa (Projeto Reflora Malpighiales, Processo 563548/2010-0).

\section{REFERÊNCIAS}

APG II 2003. An update of the Angiosperm Phylogeny Group classification for the orders and families of flowering plants: APG II. Botanical Journal of the Linnean Society 141: 399 436.

APG III 2009. An update of the Angiosperm Phylogeny Group classification for the orders and families of flowering plants: APG III. Botanical Journal of the Linnean Society 161: 105121.

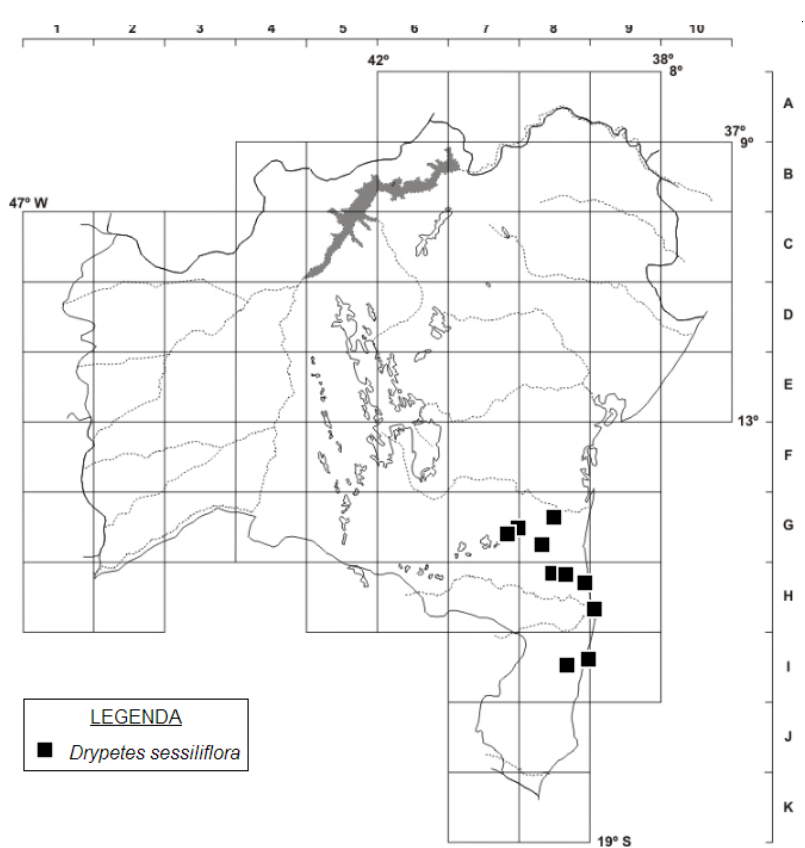

Figura 3. Distribuição geográfica de Drypetes sessiliflora no estado da Bahia.

Secco, R.S. \& Cordeiro, I. 2014. Putranjivaceae. In: Lista de Espécies da Flora do Brasil. Jardim Botânico do Rio de Janeiro. Disponível em http://floradobrasil.jbrj.gov.br/2012/FB000201; acesso em 21 jan. 2014.

Secco, R.S.; Cordeiro, I.; Senna-Vale, L.; Sales, M.F.; Lima, L.R.; Medeiros, D.; Haiad, B.S.; Oliveira, A.S.; Caruzo, M.B.R.; Carneiro-Torres, D. \& Bigio, N.C. 2012. An overview of recent taxonomic studies on Euphorbiaceae s.l. in Brazil. Rodriguésia 63: 227-242.

Steinmann, V.W. 2001. Fascículo 99: Putranjivaceae. In: Flora del Bajio Y de Regiones Adyacentes. Instituto de Ecología, A.C. Centro Regional del Bajío Pátzcuaro, Michoacán.

Stevens, P.F. 2014. Angiosperm Phylogeny Website. Versão 12, Julho 2012 [and more or less continuously updated since]. Disponível em http://www.mobot.org/MOBOT/research/ APweb/; acesso em: 21 jan. 2014.

Xi, Z; Ruhfel, B.R.; Schaefer, H.; Amorim, A.M.; Sugumaran, M.; Wurdack, K.L.; Endress, P.K.; Matthews, M.L.; Stevens, P.F.; Mathews, S. \& Davis, C.C. 2012. Phylogenomics and a posteriori data partitioning resolve the Cretaceous angiosperm radiation Malpighiales. Proceedings of the National Academy of Sciences of the United States of America 109: 17519-17524.

Wurdack, K.J.; Hoffmann, P.; Samuel, R.; Bruijn, A.; van der Bank, M. \& Chase, M.W. 2004. Molecular phylogenetic analysis of Phyllanthaceae (Phyllanthoideae pro parte, Euphorbiaceae s.l.) using plastid rbcl DNA sequences. American Journal of Botany 91: 1882-1900.

Wurdack, K.J.; Hoffmann, P. \& Chase, M.W. 2005. Molecular phylogenetic analysis of uniovulate Euphorbiaceae (Euphorbiaceae s.s.) using plastid $r b c \mathrm{~L}$ and $\operatorname{trn} \mathrm{L}-\mathrm{F}$ DNA sequences. American Journal of Botany 92: 1397-1420. 


\section{LISTA DE EXSICATAS}

Amorim, A.M. 2292, 2581, 6582; Carvalho, G.M. 4453; Fiaschi, P. 2574, 2711; Jardim, J.G. 277, 1955; Martini, A. s.n. CEPEC 122553; Mattos-Silva, L.A. 1336; Mori, S.A. 11880, 13897; Paixão, J.L. 355; Santos, F.S. 115, 658, 900; Santos, T.S. 3862; Souza, V.C. 30723; Thomas, W.W. 7486, 8714, 8751, 8806, 9160. 